\title{
A Study on Role of Adenoidectomy in Otitis Media with Effusion
}

\author{
Dr. H.S.Satish, Dr.Sarojamma, Dr.Anjan kumar A.N.
}

\begin{abstract}
Background and Objectives: Otitis media with effusion (OME) is an important and common condition in paediatric age group.It is the leading cause of hearing loss and a social morbidity in children which has long-term consequences for speech and language development. Adenoid hypertrophy is an important etiological factor in the causation of OME. The objective of this study is to study the course of the disease with respect to resolution of effusion post adenoidectomy.

Methods: This is a prospective study. The patients who presented with symptoms of adenoid hypertrophy were further evaluated for associated OME. A total of 50 patients who had adenoid hypeprtrophy and OME confirmed with preoperative PTA and tympanometry were included in the study. All patients underwent adenoidectomy under General anaesthesia. Follow up was done with repeat pure tone audiometry and tympanometry at $3^{\text {rd }}$ and $6^{\text {th }}$ months.
\end{abstract}

Results: In this study, Tympanometry showed type B curve in 54\% of ears. Postoperative audiometric assessment showed mean hearing gain at $3^{\text {rd }}$ and $6^{\text {th }}$ months being 5.32 and $4.09 \mathrm{~dB}$ respectively. At $6^{\text {th }}$ month follow up, 25 ears had A type curve, only 8 ears had B type curve and 67 ears $C$ type curve .

Conclusion: Adenoidectomy is effective in clearing middle ear effusion and causing hearing improvement in children with hypertrophied adenoids and OME.

Keywords: Otitis media effusion; Pure tone Audiometry; Tympanometry; Adenoidectomy

\section{Introduction}

Otitis media (OM) is a generic term for any inflammatory process in the middle-ear cleft behind an intact tympanic membrane (TM). The two major classes of OM are Acute OM and chronic OME. ${ }^{1}$ OME is the chronic accumulation of mucus within the middle ear and sometimes the mastoid air cell system for more than 12 weeks ${ }^{2}$. When the long term impact of OME is considered, surgical therapy is most cost effective than medical therapy for severe cases. There have been studies on role of adenoids in the causation of OME. Adenoidectomy is being increasingly used for the treatment of OME because recent studies have confirmed its effectiveness ${ }^{3}$.

In this study an effort is made to study the role of adenoidectomy in the course of OME.

\section{Materials And Methods}

The Prospective study included 50 patients presenting primarily with features suggestive of adenoid hypertrophy not responding to medical therapy who were advised adenoidectomy. These patients also had features suggestive of OME found after examination confirmed with preoperative PTA and Tympanometry. These patients underwent adenoidectomy at our Tertiary care Hospital during the period of December 2010 to October 2012.

Hearing threshold of both ears were determined by pure tone audiometry (PTA).

Hearing impairment was classified as per Clark's classification.

Tympanometry was done in all children confirming patency of external auditory canal. The graphs obtained were noted as:

- Type A - Normal Compliance

- Type B - OME

- Type C1 and C2 - Reduced compliance or early stages of OME.

X-ray Nasopharynx: Lateral view and preoperative Diagnostic Nasal Endoscopy were done to confirm adenoid hypertrophy.

Patients unresponsive to medical therapy underwent adenoidectomy under General Anaesthesia. Postoperatively all patients were treated with antibiotics, decongestants and antihistamines.

All patients were followed up at $3^{\text {rd }}$ and $6^{\text {th }}$ months after surgery with repeat Tympanometry and PTA to see for hearing improvement and occurrence of peak respectively.

\section{Results}

Our study included 50 patients with adenoids with OME who presented to our outpatient department during the study period. 
Age distribution of patients :

\begin{tabular}{|l|l|l|}
\hline Age in years & $\begin{array}{l}\text { Number of } \\
\text { patients }\end{array}$ & $\mathbf{\%}$ \\
\hline $5-10$ & 40 & 80.0 \\
\hline $11-15$ & 10 & 20.0 \\
\hline Total & 50 & 100.0 \\
\hline
\end{tabular}

Mean \pm SD: $7.48 \pm .62$

Our study included children aged 5-15 years. Majority of patients were in the age group of 5-10 years and the mean age was 7.48 years.

Distribution of Symptoms of patients:

\begin{tabular}{|l|l|l|}
\hline Symptoms & $\begin{array}{l}\text { Number of } \\
\text { patients } \\
(\mathbf{n = 5 0 )}\end{array}$ & $\%$ \\
\hline $\begin{array}{l}\text { Snoring or nasal } \\
\text { obstruction }\end{array}$ & 50 & 100.0 \\
\hline Aural fullness & 31 & 62.0 \\
\hline
\end{tabular}

All patients had nasal obstruction/snoring. $62 \%$ of patients had aural fullness.

Distribution of Signs of patients :

\begin{tabular}{|c|l|l|}
\hline Signs & $\begin{array}{l}\text { Number of } \\
\text { patients } \\
(\mathbf{n = 5 0 )}\end{array}$ & $\mathbf{\%}$ \\
\hline TM appearance & & \\
\hline$\bullet \quad$ Dull, amber & 47 & 94.0 \\
\hline$\bullet \quad$ Retraction & 32 & 64.0 \\
\hline$\bullet \quad$ Air bubbles & 8 & 16.0 \\
\hline X-ray nasopharynx & 50 & 100.0 \\
\hline $\begin{array}{l}\text { Diagnostic Nasal Endoscopy } \\
\text { Adenoid hypertrophy grading }\end{array}$ & & \\
\hline$\bullet \quad$ Grade 1 & 2 & 4.0 \\
\hline$\bullet \quad$ Grade 2 & 25 & 50.0 \\
\hline$\bullet \quad$ Grade 3 & 23 & 46.0 \\
\hline
\end{tabular}

On otoscopy, dull , amber coloured TM was the common finding seen in $94 \%$ of cases. Retraction of TM was seen in $64 \%$. Air bubbles were seen only in 16\%. Diagnostic nasal endoscopy showed grade 2 hypertrophy in $50 \%$, grade 3 in $46 \%$ and grade 1 only in $4 \%$ of patients. (According to Endoscopic Adenoids grading system ${ }^{4}$ )

Distribution of Tympanometry Curve type of patients :

\begin{tabular}{|c|c|c|c|c|c|}
\hline \multirow[b]{2}{*}{ Curve type } & \multirow{2}{*}{$\begin{array}{l}\text { Pre operative } \\
\text { Initial } \\
\text { (n=100 EARS) }\end{array}$} & \multicolumn{2}{|l|}{ Post operative } & \multirow[b]{2}{*}{$\%$ change } & \multirow[b]{2}{*}{$P$ value } \\
\hline & & $\begin{array}{l}3^{\text {rd }} \text { month } \\
(n=100 \text { EARS })\end{array}$ & $\begin{array}{l}6^{\text {th }} \text { month } \\
(n=100 \text { EARS })\end{array}$ & & \\
\hline A & 0 & $21(21.0 \%)$ & $25(25.0 \%)$ & $+25.0 \%$ & $<0.001 * *$ \\
\hline $\mathrm{B}$ & $54(54.0 \%)$ & $12(12.0 \%)$ & $8(8.0 \%)$ & $-46.0 \%$ & $<0.001 * *$ \\
\hline $\mathrm{C}$ & $46(46.0 \%)$ & $67(67.0 \%)$ & $67(67.0 \%)$ & $+21.0 \%$ & $<0.001 * *$ \\
\hline
\end{tabular}




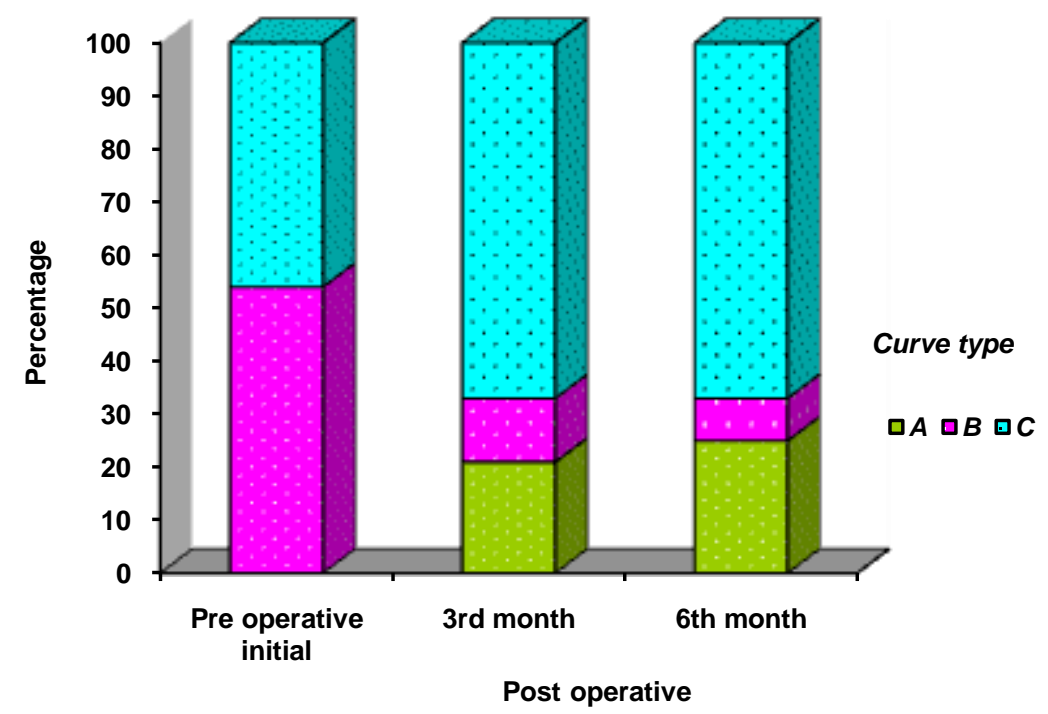

Graph showing distribution of Tympanometry Curve types

A type Tympanometry curve was seen in none of the ears preoperatively which changed to 21 and 25 ears at $3^{\text {rd }}$ and $6^{\text {th }}$ months respectively. B type curve was seen in majority of the ear preoperatively which decreased to 12 and 8 ears at $3^{\text {rd }}$ and 6th months respectively. C type curve was seen in 46 ears which increased to 67 ears at both $3^{\text {rd }}$ and $6^{\text {th }}$ months respectively. The change in curve types were found to be statistically significant.

Comparison of Pure Tone Audiometry of patients (Based on number of ears):

\begin{tabular}{|l|l|l|l|}
\hline Pure Tone Audiometry & Pre operative & \multicolumn{2}{|l|}{ Post operative } \\
\cline { 3 - 4 } & Initial & $\mathbf{3}^{\text {rd }}$ month & $\mathbf{6}^{\text {th }}$ month \\
\hline Min-Max & $23.00-32.00$ & $17.00-28.00$ & $16.00-29.00$ \\
\hline Mean \pm SD & $27.76 \pm 2.34$ & $22.44 \pm 2.79$ & $23.07 \pm 2.79$ \\
\hline $95 \%$ CI & $5.11-5.52$ & $4.36-5.01$ & $0.91-0.34$ \\
\hline P value & $<0.001^{* *}$ & $<0.001^{* *}$ & $<0.001^{* *}$ \\
\hline Pre-op vs $3^{\text {rd }}$ month & $\begin{array}{l}\text { PTA is significantly decreased in } 3^{\text {rd }} \text { month from pre- } \\
\text { op with P }<0.001^{* *}\end{array}$ \\
\hline Pre-op vs $6^{\text {th }}$ month & $\begin{array}{l}\text { PTA is significantly decreased in } 6^{\text {th }} \\
\text { op with P }<0.001^{* *}\end{array}$ \\
\hline
\end{tabular}

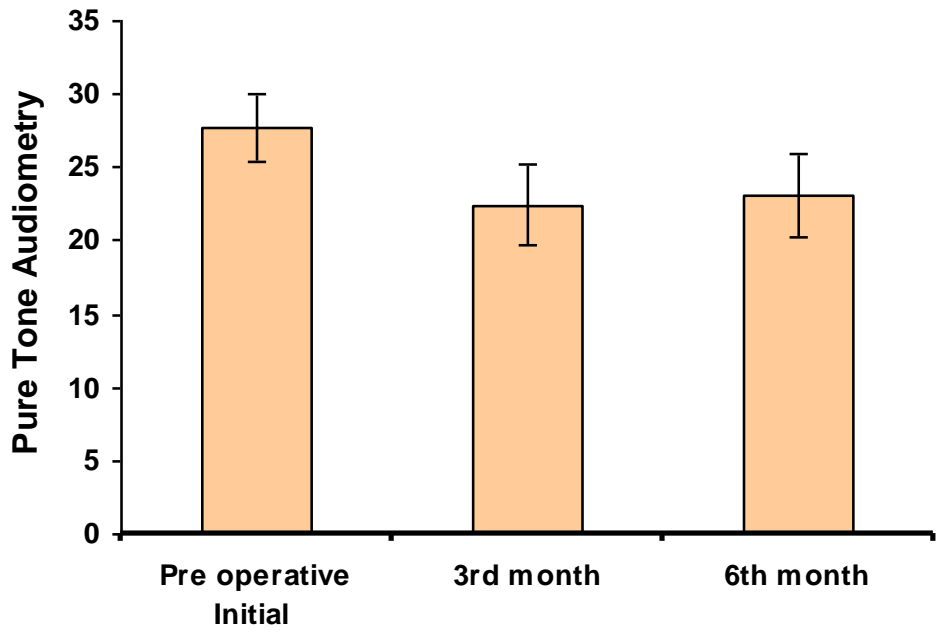

Post operative

Graph showing comparision of Pure Tone Audiometry 
Most of the children in our study had mild hearing loss according to Clark's classification and average hearing loss was $27.76 \mathrm{~dB}$. Mean hearing gain at $3^{\text {rd }}$ and $6^{\text {th }}$ month post operatively were 5.32 and 4.09 respectively which ware statistically significant.

Statistical Methods: Analysis of variance (ANOVA) ,Student t test (two tailed, dependent) and Paired proportion test has been used to find the significance of proportion from initial with $6^{\text {th }}$ month.

\section{Discussion}

Adenoidectomy is being increasingly used for the treatment of OME because recent studies have confirmed its effectiveness ${ }^{1} \mathrm{~A}$ prospective study of 50 cases of adenoid hypertrophy with associated OME was studied to assess the effect of adenoidectomy alone in improvement of hearing and tympanogram . All patients underwent adenoidectomy under general anaesthesia.

Our study included children aged 5-15 years. Majority were in the age group of 5-10 years and the mean age was 7.48 years. The adenoid appears to be at its largest in the seven-year-old age group ${ }^{5}$. In our study, there is slight male preponderance when compared to females. $\quad$. However, Paradise et al (1997) reported no apparent gender based difference in the incidence of $\mathrm{SOM}^{6}$. All patients had nasal obstruction/snoring. Hard of hearing was the common symptom related to ear, followed by fullness. On otoscopy, dull, amber coloured TM was the common finding seen in $94 \%$ of cases.

Tympanometry is widely used in screening for OME. As suggested by Fiellau-Nickolajsens classification in 1983, a middle ear pressure of $<100 \mathrm{~mm} \mathrm{H}_{2} \mathrm{O}$ was considered abnormal in our study. According to Renvall et al stapedial reflex is considered too sensitive to be used as a screening test in the diagnosis of $\mathrm{OME}^{7}$

In our study, most children had type B curve. The change in curve types was found to be statistically significant. Dempster and Mackenzie (1991) ${ }^{8}$ showed that only $2 \%$ of children with a bilateral hearing loss of 25 $\mathrm{dB}$ or more did not have flat, type B tympanograms $(\mathrm{p}=0.002)$. Combined sensitivity of otoscopy and tympanometry type B curve is $98 \%$. Maw in 1986 observed that adenoidectomy alone produced no peak/peak conversion in $29.8 \%$ of children ${ }^{9}$. According to Clark's classification average hearing loss was $27.76 \mathrm{~dB}$. OM causes moderate conductive hearing loss, the average loss being $27 \mathrm{~dB}^{10}$. In Glasgow studies by Dempster \& Mackenzie (1991) have shown $26 \mathrm{~dB}$ hearing loss ${ }^{11}$.

Mean hearing gain at $3^{\text {rd }}$ and $6^{\text {th }}$ month post operatively were 5.32 and 4.09 respectively in our study which was statistically significant. According to N A Black et $\mathrm{al}^{12}$, the mean $\mathrm{dB}$ gain at 7 weeks and 6 months are 4.5 and $3.5 \mathrm{~dB}$ respectively.

Gates and others ${ }^{1}$ randomly assigned 491, 4-9-year-old children with OME to surgical control, tympanostomy tube, adenoidectomy or adenoidectomy plus tympanostomy tube. The children in the two adenoidectomy groups experienced significantly less time with effusion and fewer repeat surgeries throughout the 2-year follow-up period than those who did not undergo adenoidectomy.

Coyle et $\mathrm{al}^{13}$ also concluded that adenoidectomy is a useful procedure for correction of medically resistant chronic OME and should be considered as the first line procedure when surgical treatment is chosen.

Thus the evidence supports the conclusion that adenoidectomy is effective in improving the natural history of OME.

All patients were regularly followed up postoperatively. During follow up there was improvement in hearing and tympanogram which were statistically significant.

\section{Conclusion}

- Adenoidectomy is being increasingly used for the treatment of OME because recent studies have confirmed its effectiveness.

- The mean age of occurrence of OME with adenoid hypertrophy according to our study is 7.48 years.

- The improvement in hearing and tympanogram post adenoidectomy at $3^{\text {rd }}$ and $6^{\text {th }}$ months was statistically significant.

- OME leads to hearing impairment in paediatric age group. It's a social morbidity. Hence adenoidectomy in children having hypertrophied adenoids at this stage of the disease effectively prevents hearing impairment.

- To conclude, according to our study adenoidectomy in hypertrophied adenoids with OME is simple and effective procedure in the resolution of OME and improvement in hearing postoperatively.

\section{Bibliography}

[1] Cummings - Andrew F. Inglis Jr. George A. Gates Cummings Otolaryngology - Head and Neck surgery, $4^{\text {th }}$ edition, Elsevier Mosby, 2005, vol - 4,Pg - 4445-4464

[2] George Browning,Scott-Brown's Otorhinolaryngology - Head and Neck Surgery, $7^{\text {th }}$ edition, Hodder Arnold, 2008,vol - 1,pg- 877 $-882$

[3] Eavey RD. Abnormalities of the neonatal ear: otoscopic observations, histological observations, and a model for contamination of the middle ear by cellular contents of amniotic fluid. Laryngoscope 1993; 103: 1-31 
[4] Parikh, SR; Coronel, M; Lee, JJ \& Brown, SM. (2006). Validation of a new grading system for endoscopic examination of adenoid hypertrophy. Otolaryngology - Head and Neck Surgery, Vol.135, No.5, pp. 684-687.

[5] Vogler RC, Ii FJ, Pilgram TK. Age-specific size of the normal adenoid pad on magnetic resonance imaging. Clinical Otolaryngology and Allied Sciences. 2000; 25: 392-5.

[6] Paradise et al. OM in 2253 Pittsburgh-area infants: Prevalence and risk factors during the first 2 years of life. Pediatrics 1997; 99: 318.

[7] N A Blac et al. randomised controlled trial of surgery for glue ear, BMJ Vol 30016 June 1990;300:1551-6

[8] Dempster JH et al. Tympanometry in detection of hearing impairments associated with OME. Clin Otolaryngol 1991; 16: 157-159.

[9] Maw AR and Herod F. Otoscopic impedance and audiometric findings in glue ear treated by adenoidectomy and tonsillectomy. A prospective randomized study. Lancet; I 1986; 1399-1402.

[10] Bluestone CD and Klein JO. Otitis media in infants and children. 2nd edition ed. Philadelphia. WB Saunders Company 1995; 11:711

[11] Wiatrak BJ, Woolley AL. Pharyngitis and adenotonsillar disease. In: Cummings CW. Chap 12; Pediatric Otolaryngology Head and Neck Surgery, 3rd edition, Missouri, Mosby.1998; 188-211.

[12] N A Blac et al. randomised controlled trial of surgery for glue ear, BMJ Vol 30016 June 1990;300:1551-6

[13] Coyle PC. Croxford R, MC Isaac W, Feldman W, Friedberg J. The role of Adjuvant adenoidectomy \& tonsillectomy in the out of the insertion of tympanostomy tube. N Engl J Med 2004; 344: 1188-95. 